continue to flourish ; it interferes with no national organisation, it can give advice to newly formed national societies, and it can bring together for international study the different problems with which different countries are confronted.

The prevention of blindness takes an entirely different aspect according to the nature of the country in which it is considered, whether temperate or tropical. In temperate countries such as Great Britain, France, Germany and the greater part of the United States of America the causes of blindness from infectious disease are diminishing, but from industrial eye injuries and refraction errors are increasing. However, in tropical countries the campaign against the causes of blindness is an infinitely more serious and urgent problem. To the severe endemic diseases (infectious conjunctivitis, small-pox, gonorrhoea, trachoma, syphilis) are added the starvation disease, xerophthalmia, and the results of quackery.

The International Association for the Prevention of Blindness had its origin at the XIII Concilium Ophthalmologicum, and therefore among ophthalmologists; however, the necessity of social measures to effect some of the objects of the Association seems to call for the co-operation of sub-committees composed of industrialists and other non-medical members.

Statistics of the number of blind per 100,000 of the population vary from 776 in the case of Egypt, to 32 in the case of New Zealand. When an increase in the proportion of blind appears in statistics it does not necessarily mean that there is any real increase of blindness, but that greater care is taken in the registration of blind persons.

This important report is full of interest; it deserves study by all social workers, as well as by officials of all Ministries of Health, and by all Medical Officers of Health.

\title{
Variations on a Theme
}

Jaeger 1 may sometimes prove a stumbling block even to those with adequate near vision, and when this occurs the patient may unwittingly be subjecting himself to what is almost a form of psycho-analysis. A paragraph familiar to many ophthalmologists begins with the words "It was upon a delicious summer morning." Several, of the bright young thing type, particularly if they are in their first season, will render this "It was upon a delirious summer evening." A solicitor who specialised in divorce work, read it as "It was upon a delicate matter," whereas a woman who was verging upon religious mania beamed all over her face and read "It was upon a dedication morning." Another paragraph, Jaeger 4 this time, which begins, "I have always suspected 
public taste," is fairly frequently rendered "I have always respected public taste," by Sisters of Mercy and just those nice kindly people who are incapable of suspecting anybody or anything.

The sterner type comes into its own with the recently published Jaeger 1, beginning " Hope they say deserts us at no period of our existence." The first word of this is changed into hops and the reader very often appears as though he believed the statement or at any rate hoped that it was true. Aviators, particularly if they have been flying over sandy wastes, turn the word deserts into a noun and for them of course "hops" have a different significance.

Whether these mistakes can be turned to any practical account in the technique of psycho-analysis is more than doubtful, but their occasional occurrence serves to relieve the tedium of hearing the same familiar sentences read over and over again.

\section{ABSTRACTS}

\section{MISCELLANEOUS}

(1) Cargill, L. Vernon (London).- The Ophthalmological Society of the United Kingdom). Medical Press and Circular, January, 1937.

(1) The first of the third series of articles on British Medical Societies, which are a most interesting feature of the Medical Press and Circular is indicated in the title of our abstract. Mr. Cargill is to be congratulated on the excellent epitome of the history of the society during its life of 57 years, which he has written. $\mathrm{He}$ has obviously taken great trouble in consulting early minute books and the volumes of Transactions and, of course, as he joined the Society when it was only ten years old he can speak with firsthand knowledge of the greater part of its career.

The paper is illustrated by reproductions of portraits of Sir William Bowman and Edward Nettleship together with the Presidential Badge. We hope that all ophthalmic surgeons will read it.

As far back as 1884 a committee was appointed to inquire into the prevention of blindness from ophthalmia neonatorum and a deputation headed by Sir William Bowman and Jonathan Hutchinson waited on the authorities of the Lccal Government Board. In the Transactions for the following year will be found 